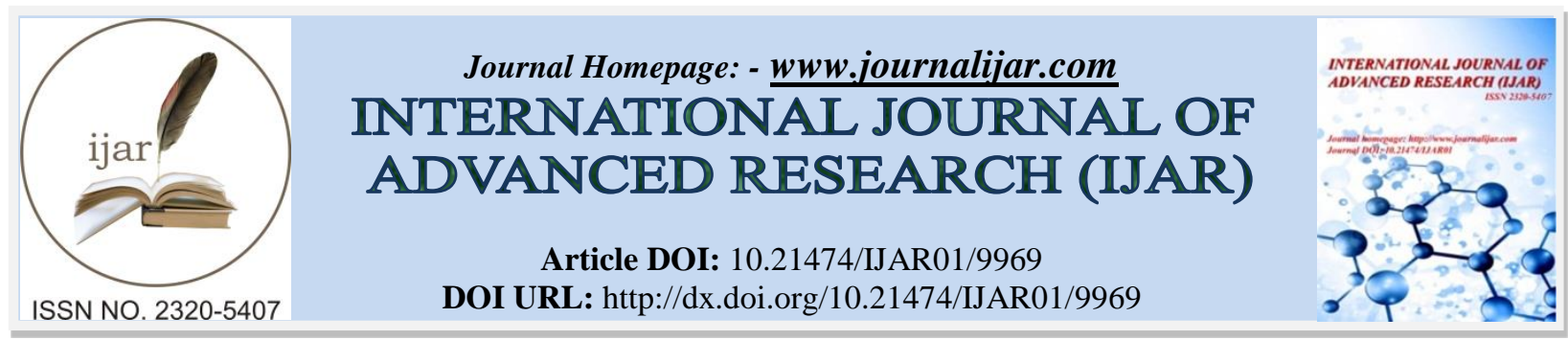

RESEARCH ARTICLE

\title{
FREE CONVECTION IN A SATURATED POROUS MEDIUM WITH VARYING TEMPERATURE ADJACENT TO A VERTICAL IMPERMEABLE PLATE AT $4^{\circ} \mathrm{C}$.
}

\section{Gérard Degan $^{1}$, Franck M. Egboho ${ }^{2}$ and Christian D. Akowanou ${ }^{3}$.}

1. National University of Science, Technology, Engineering and Mathematics, BP2282, Goho Abomey, Benin.

2. Laboratory of Energetics and Applied Mechanics, University of Abomey-Calavi, 01BP2009, Cotonou, Benin.

3. National University of Science, Technology, Engineering and Mathematics, BP2282, Goho Abomey, Benin.

\section{Manuscript Info}

\section{Manuscript History}

Final Accepted: 07 October 2019

Published: November 2019

Key words:-

Porous medium, anisotropy, , maximum

density, boundary la-yer regime.
Received: 05 September 2019

\begin{abstract}
Several studies on convective flow in boundary layer regime were analyzed for the case of an isothermal vertical plate or variable temperature dipped in a porous medium saturated with water at $3.98^{\circ}$ C. However, in the situations where the vertical plate is at a constant temperature of $3.98^{\circ} \mathrm{C}$ and the porous medium saturated with water at the variable temperature are also realistic. In this study we are interested in the study of natural convection around a vertical plate at a temperature of $3.98{ }^{\circ} \mathrm{C}$ under the conditions previously described. The influence of the anisotropic parameters such as the permeability ratio and the anisotropic angle, as well as the Nusselt number and the effect of the maximum density were analyzed. The main conclusion is that the flow is downward, and the convective heat transfer rate admits a minimum and a maximum depending on the different parameters. The governing equations and boundary conditions were solved numerically by the $4^{\text {th }}$ order of Runge-Kutta and shooting method before the scaling analysis.
\end{abstract}

Copy Right, IJAR, 2019,. All rights reserved.

\section{Introduction:}

The study of free convection in a saturated porous medium bounded by a vertical plate has received much attention in the past following decades. Various cases of free and mixed convection in geothermal systems have been studied by Cheng and Minkowyz [1]. Free convection from a vertical flat plate embedded in a saturated porous medium has investigated by them. The wall temperature varies as power function of the distance from the origin. Many authors have found similarity solution for wall temperature varying as power function or exponential function. It is the case of Johnson and Chen[2], and Ramilison and al.[3]. A great deal of work has been done concerning the case where the porous medium is saturated with a fluid at the temperature of its maximum density. This is particulary the case of water at $4^{\circ} \mathrm{C}$. Kumaran and Pop [4] have studied the natural convection on a heated vertical plate embedded in a saturated porous medium by water near $4^{\circ} \mathrm{C}$. In this work, we propose to study natural convection from an isothermal vertical plate near $4^{\circ} \mathrm{C}$ embedded an anisotropic porous medium. The wall-ambient temperature difference varies as power function of the distance from origin of $\mathrm{x}$ axis.

\section{Governing equations}

The physical situation and coordinate system is describing in Figure $\mathrm{N}^{\circ} 1$. It consists of a vertical plate embedded in an anisotropic porous medium saturated by some water near its maximum density. The fluid is flowing in the 
direction of $x^{\prime}$. Principal axes are shown with extremum permabilities $K_{1}$ and $K_{2}$. The anisotropic angle $\theta$ giving the orientation of the principal axis labelled $\mathrm{K}_{2}$ with respect to the horizontal $\mathrm{y}^{\prime}$ axis. We defined the anisotropic ratio $\mathrm{K}^{*}=\mathrm{K}_{1} / \mathrm{K}_{2}$. The following approximations are adopted to simplify the mathematical model: Water is an incompressible Newtonian fluid; the engendered flow is laminar, permanent and two-dimensional; Viscous and pressure's strengths are neglected; the thermo-physical properties of the fluid are constants and are estimated at the reference temperature.

The density of the fluid varies non-linearly with the temperature; the porous medium is anisotropic in permeability; the empirical Darcy's law is assumed. The density according to the temperature is expressed by the parabolic model used by A. Mahidjiba et al. [5] and W. Zheng et al [6]:

$$
\frac{\rho-\rho_{\max }}{\rho_{\max }}=-\beta\left(T^{\prime}-T_{\max }^{\prime}\right)^{2}
$$

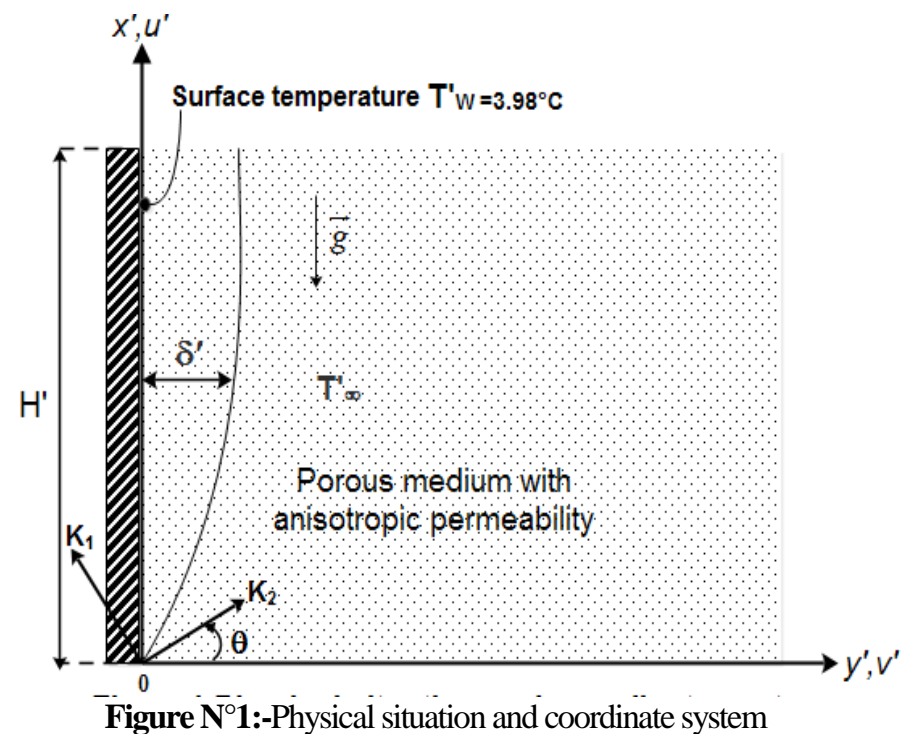

Where $T_{\max }^{\prime}=3.98^{\circ} \mathrm{C}$ is a temperature of the maximum density of the water. the coefficient of thermal volume expansion of the fluid $\beta=8.0 \times 10^{-6}\left({ }^{\circ} \mathrm{C}\right), \rho_{\max }$ is the maximum density of the water. The resulting equation is valid for the range $\left[0-8^{\circ} \mathrm{C}\right][6]$. With our previous assumptions, the basic equations are :

$\nabla \cdot \overrightarrow{V^{\prime}}=0$

$\overrightarrow{V^{\prime}}=\frac{\overline{\bar{K}}}{\mu}[-\nabla P+(\Delta \rho) \vec{g}]$

$\left(\rho c_{p}\right)_{f} \nabla \cdot\left(V^{\prime} \cdot T^{\prime}\right)=k \nabla^{2} T^{\prime}$

Where V' vector is Darcy velocity, $\mu$ and $C_{P}$ are the viscosity and specific heat of the convective fluid, $g$ the gravity vector, $\left(\rho C_{P}\right)_{f}$ is the total heat capacity of the fluid per unit volum, $k$ is the effective thermal conductivity of the saturated porous medium, $\mathrm{P}$ is the fluid pressure, $\mathrm{T}^{\prime}$ is the temperature and $\overline{\bar{K}}$ is the second-order permeability tensor.

$$
\overline{\bar{K}}=\left[\begin{array}{ll}
K_{1} \cos ^{2} \theta+K_{2} \sin ^{2} \theta & \left(K_{1}-K_{2}\right) \sin \theta \cos \theta \\
\left(K_{1}-K_{2}\right) \sin \theta \cos \theta & K_{1} \sin ^{2} \theta+K_{2} \cos ^{2} \theta
\end{array}\right]
$$

From Eq.1 it appears that the density difference involved in Eq.3 becomes:

$$
\Delta \rho=\rho_{\max } \times \beta\left[\left(T^{\prime}-T_{\max }^{\prime}\right)^{2}-\left(T_{\infty}^{\prime}-T_{\max }^{\prime}\right)^{2}\right]
$$

The governing equations in primitives variables (axis ox',oy') may be expressed as: 
$\frac{\partial u^{\prime}}{\partial x^{\prime}}+\frac{\partial v^{\prime}}{\partial y^{\prime}}=0$

$a \frac{\partial u^{\prime}}{\partial y^{\prime}}+c\left(\frac{\partial u^{\prime}}{\partial x^{\prime}}-\frac{\partial v^{\prime}}{\partial y^{\prime}}\right)-b \frac{\partial v^{\prime}}{\partial x^{\prime}}=\frac{K_{1} g \rho_{\max } \beta}{\mu} \frac{\partial}{\partial y^{\prime}}\left[\left(T^{\prime}-T_{\max }^{\prime}\right)^{2}-\left(T_{\infty}^{\prime}-T_{\max }^{\prime}\right)^{2}\right]$

$u^{\prime} \frac{\partial T^{\prime}}{\partial x^{\prime}}+v^{\prime} \frac{\partial T^{\prime}}{\partial y^{\prime}}=\alpha\left(\frac{\partial^{2} T^{\prime}}{\partial x^{\prime 2}}+\frac{\partial^{2} T^{\prime}}{\partial y^{\prime 2}}\right)$

We must notice that:

$a=\cos ^{2} \theta+K^{*} \sin ^{2} \theta$

$b=\sin ^{2} \theta+K^{*} \cos ^{2} \theta$

$c=\left(1-K^{*}\right) \sin \theta \cos \theta$

More over, in boundary layer regime, the flowing is restricted to a thin thickness $\delta$ of boundary layer along the vertical surface. In this area of study, $\left(\delta x \mathrm{H}^{\prime}\right)$ we have: $\partial^{2} / \partial x^{2} \ll \partial^{2} / \partial y^{2}$. In a boundary layer region, the basic equations in two dimensional laminar convection flow are the following:

$\frac{\partial u^{\prime}}{\partial x^{\prime}}+\frac{\partial v^{\prime}}{\partial y^{\prime}}=0$

$a \frac{\partial u^{\prime}}{\partial y^{\prime}}=\frac{K_{1} g \rho_{\max } \beta}{\mu} \frac{\partial}{\partial y^{\prime}}\left[\left(T^{\prime}-T_{\max }^{\prime}\right)^{2}-\left(T_{\infty}^{\prime}-T_{\max }^{\prime}\right)^{2}\right]$

$u^{\prime} \frac{\partial T^{\prime}}{\partial x^{\prime}}+v^{\prime} \frac{\partial T^{\prime}}{\partial y^{\prime}}=\alpha \frac{\partial^{2} T^{\prime}}{\partial y^{\prime 2}}$

By defining the stream function $\psi$ associated with the behavior of the filtration velocity:

$$
u^{\prime}=\frac{\partial \psi^{\prime}}{\partial y^{\prime}} \text { and } v^{\prime}=-\frac{\partial \psi^{\prime}}{\partial x^{\prime}}
$$

The conservation equations for mass (Eq.13) is automatically satisfied. By introducing the relations (Eq.16) into the equations (Eq.14) and (Eq.15), we obtain respectively the following expressions:

$$
\begin{aligned}
& \frac{\partial^{2} \psi^{\prime}}{\partial y^{\prime 2}}=\frac{1}{a} \frac{K_{1} g \rho_{\max } \beta}{\mu} \frac{\partial}{\partial y^{\prime}}\left[\left(T^{\prime}-T_{\max }^{\prime}\right)^{2}\left(T_{\infty}^{\prime}-T_{\max }^{\prime}\right)^{2}\right] \\
& \frac{\partial^{2} T^{\prime}}{\partial y^{\prime 2}}=\frac{1}{\alpha}\left(\frac{\partial \psi^{\prime}}{\partial y^{\prime}} \frac{\partial T^{\prime}}{\partial x^{\prime}}-\frac{\partial \psi^{\prime}}{\partial x^{\prime}} \frac{\partial T^{\prime}}{\partial y^{\prime}}\right)
\end{aligned}
$$

The thermal conditions on the borders spell:

$$
y^{\prime}=0, T^{\prime}=T_{\infty}^{\prime}+\Delta T\left(x^{\prime} \gg 0\right)
$$

$y^{\prime} \rightarrow \infty, T^{\prime}=T_{\infty}^{\prime}$

$\Delta T=T_{W}^{\prime}-T_{\infty}^{\prime}=N x^{\prime n}$ where $\mathrm{N}$ is a real number. Under the influence of the gradient of temperature, it is born an unidirectional flow along the vertical surface. It is advisable to write then:

$y^{\prime}=0, v^{\prime}=0$

Far from the vertical plate, the flow velocity is the one of the free flow which is developed in the direction (Oy'), it spell:

$y \rightarrow \infty, u^{\prime}=0$

After a scaling analysis following Vasseur and al.[7] and Bejan[8] we introduce the similar variables below : 


$$
f(\eta)=\frac{\psi^{\prime}}{\alpha\left(\frac{R a_{x^{\prime}}}{a}\right)}, \eta=\frac{y^{\prime}}{x^{\prime}}\left(\frac{R a_{x^{\prime}}}{a}\right)^{1 / 2} \text { and } \theta(\eta)=\frac{T^{\prime}-T_{\infty}^{\prime}}{\Delta T^{\prime}}
$$

We also defined the inversion parameter $\mathrm{R}$ as:

$R=\frac{T_{\max }^{\prime}-T_{\infty}^{\prime}}{\Delta T^{\prime}}$

In our case $\mathrm{R}=1$

The governing equations in similar variables become:

$$
\left[\begin{array}{l}
f^{\prime}-(\theta-1)^{2}+1=0 \\
\theta^{\prime \prime}+\frac{2 n+1}{2} f \theta^{\prime}+n f^{\prime}(\theta-1)=0 \\
\eta=0 ; \theta=1 ; f=0 \\
\eta \rightarrow \infty ; \theta=0
\end{array}\right.
$$

Before discussing the computed results, the basic transport quantities of interest are determined, in term of similarity variables, as follows:

$N u_{x^{\prime}}=\left[\frac{R a_{x^{\prime}}}{a}\right]^{1 / 2}\left\{\theta^{\prime}(0)\right\}$

Where $N u_{x^{\prime}}$ is a local Nusselt number and the thermal boundary layer relative thickness is obtained from Eq.27.

$$
\frac{\delta^{\prime}}{x^{\prime}}=\eta_{\delta^{\prime}}\left(\frac{a}{R a_{x^{\prime}}}\right)^{1 / 2}
$$

$\eta_{\delta^{\prime}}$ is a point where $\theta$ might have a value of 0.01 .

\section{Numerical method and code validation}

Eq. 28 with boundary conditions were solved with shooting method and Runge Kutta of 4th order. Firstly, we solved the case $\Delta T=N x^{\prime n}, \mathrm{R}=0$ and $\mathrm{n}=1 / 2$ which were resolute analytically by Kumaran [4] and we compared these results. See table 1 . Secondly, by noticing that for $\Delta T=N x^{\prime n}$, and $\mathrm{R}=0$ the governing equations amounts in:

$$
\left\{\begin{array}{c}
f^{\prime}-(R-\theta)^{2}+R^{2}=0 \\
\theta^{\prime \prime}+\frac{(q n+1)}{2} f \theta^{\prime}-n f^{\prime}(\theta-R)=0 \\
\eta=0, \theta=1, f=0 \\
\eta \rightarrow \infty, \theta=0
\end{array}\right.
$$

Where $\mathrm{q}$ is the degree of the expression of the variation of the density according to the temperature. The model used for the present study is parabolic $(\mathrm{q}=2)$. The linear model $(\mathrm{q}=1)$ was numerically solved by Cheng et al. for the natural convection on a vertical plate in isotropic case[1]. We reported also their results in the table 2.

Table 1:-Comparison with results of Cheng and Minkowycz [1]

\begin{tabular}{|l|l|l|l|}
\hline & Cheng and Minkowycz [14] & Present method & Present work \\
\hline & $\mathrm{q}=1$ & $\mathrm{q}=1$ & $\mathrm{q}=2$ \\
\hline $\mathrm{n}$ & $\theta^{\prime}(0)$ & $\theta^{\prime}(0)$ & $\theta^{\prime}(0)$ \\
\hline 0 & -0.444 & -0.444 & -0.377 \\
\hline $1 / 3$ & -0.6788 & -0.677 & -0.615 \\
\hline
\end{tabular}


Taking into consideration its results of table 1 and 2, we concluded that the numeric code was very substantial of the point of view of the precision because of the gaps relatively very weak observed.

Table2:-Comparison with results of Kumaran

\begin{tabular}{|l|l|l|}
\hline & Kumaran,2006 & Present numerical code \\
\hline$-\theta^{\prime}(0)$ & $\frac{\sqrt{2}}{2}$ & 0.7071283939991931 \\
& $-\sqrt{2} \ln 0.01$ & \\
\hline$\eta_{\delta}$ & 5.964584666059244 \\
\hline
\end{tabular}

\section{Results and discussion:-}

Fig.2 displays the velocity profile for a range of values of $n$ and $\eta$. It is observed that the velocity increases from the leading edge of the vertical plate and reached rapidly its maximum value when the temperature exponent $n$ is made high enough. For lower values of $n$, the velocity increases with $\eta$ and tends asymptotically to its maximum value.It is easy to notice that for $\mathrm{n}$ ranging from 0 to 10 the flow is directed downwards as shown in Fig.2. Therefore, it is when the temperature of the porous medium is constant and does not vary $(n=0)$ that the velocity is the highest. The velocity in the porous medium is stronger at the beginning of the plate and it decreases more and more far from the vertical plate until it vanishes whatever the value of n. Fig.2 also shows that the convective movement, characterized by the velocity of the flow in the porous medium, extends from the plate to a distance away from the plate as a function of $\mathrm{n}$. the larger is the $\mathrm{n}$, the shorter is the distance. Otherwise it is the thickness of the dynamic boundary layerThe variation of the non-dimensional temperature in the porous medium with the similarity variable $\eta$ is presented in Fig.3 for various values of the temperature exponent $n$. From Fig.3, when $n$ increases, the nondimensional temperature in the porous medium decreases drastically. It reveals that the heat diffuses from the vertical plate into the porous medium. The influence of the temperature exponent $n$ on the relative boundary layer thickness is shown in Fig.4. It is observed that the relative boundary layer thickness decreases drastically when the temperature exponent $n$ increases and reaches its minimum value when $n$ is made higher enough. Hence, the fluid nearest to the plate warms up, decreases its density and moves downwards according to Archimede's law. So, in that case, the formation of a thin boundary-layer along the plate is observed.

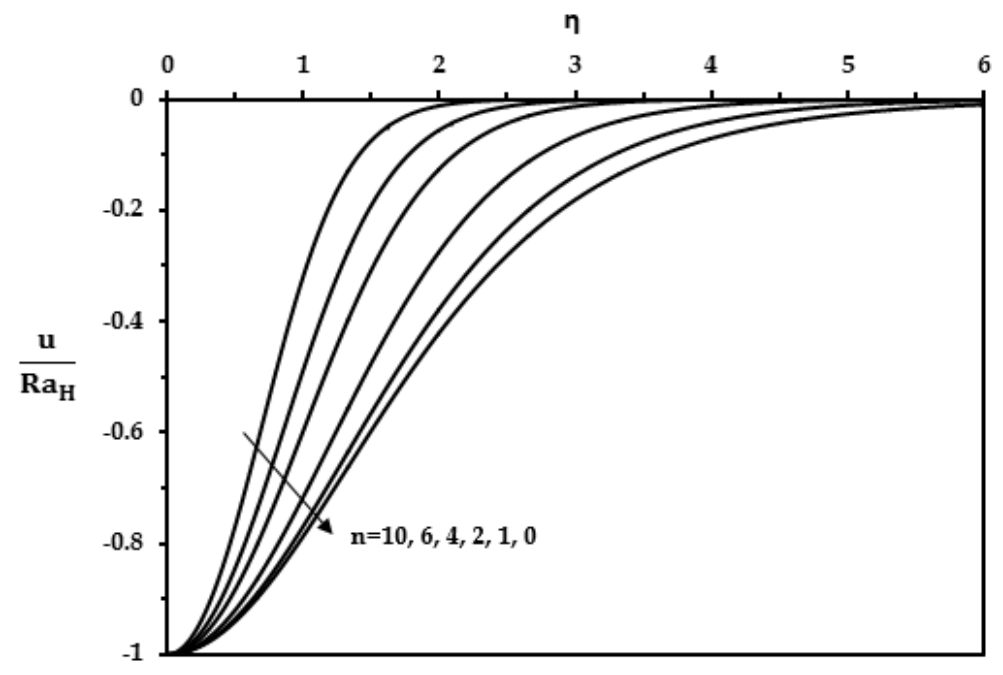

Figure 2:-Variation of the velocity in the porous medium for various values of $\mathrm{n}$ in isotropic case 


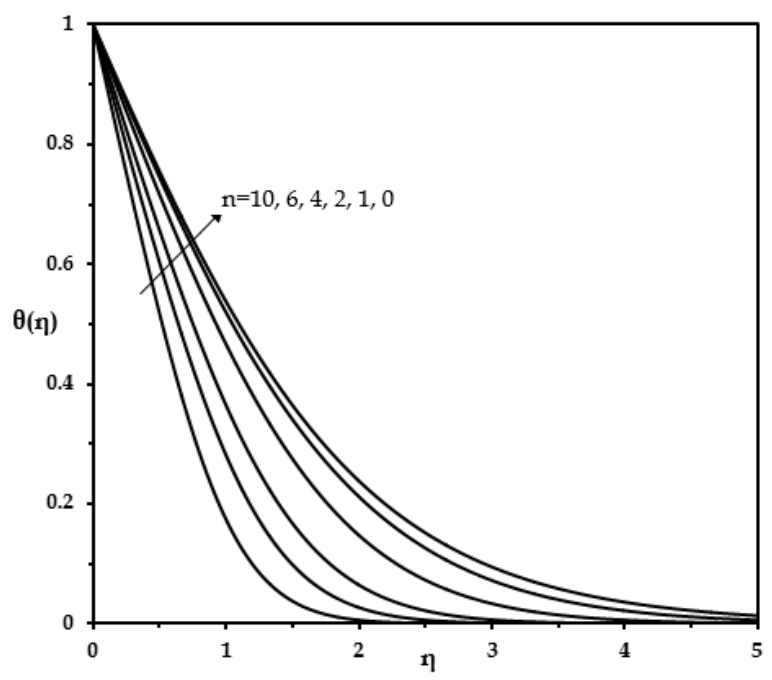

Figure 3:-Variation of the non-dimensional temperature in the porous medium forvarious values of $\mathrm{n}$ in isotropic case $(\mathrm{R}=1)$

Fig.5 shows the effect of the orientation angle $\theta$ on the variation of the average Nusselt number $\overline{\mathrm{Nu}}$ with the temperature exponent $n$ when $K^{*}=0.1$. When $n=0$, the average Nusselt number increases with the orientation angle $\theta$ defined as the angle between the horizontal direction and the principal axis with permeability $K_{2}$. It is observed from Fig. 5 that, the average Nusselt number increases and reaches its maximum with the temperature exponent $n$ when $\theta$ increases from $0^{\circ}$ to $90^{\circ}$. Thus, it follows from this result that a maximum (minimum) convective heat transfer is reached when the orientation of the principal axis with higher permeability of the anisotropic porous medium is parallel (perpendicular) to the gravity. Fig. 6 shows the effect of the permeability ratio $K^{*}$ on the variation of the average Nusselt number $\overline{\mathrm{Nu}}$ with the temperature exponent $n$ when $\theta=45^{\circ}$. When $n=$ 0 , the average Nusselt number decreases when the permeability ratio $K^{*}$ increases. It follows in that case, that lower value of $K^{*}$ favors the heat transfer.

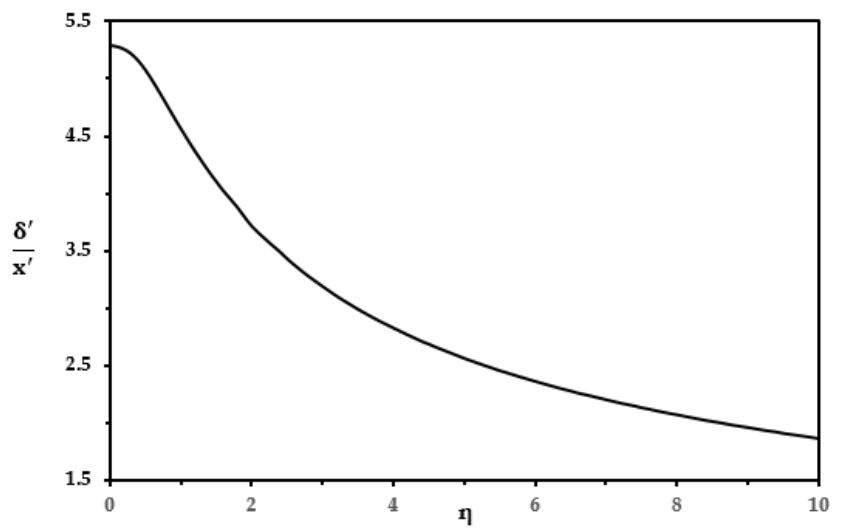

Figure 4:-Variation of the relative boundary layer thickness on the vertical plateversus $n$ in isotropic case $(R=1)$ 


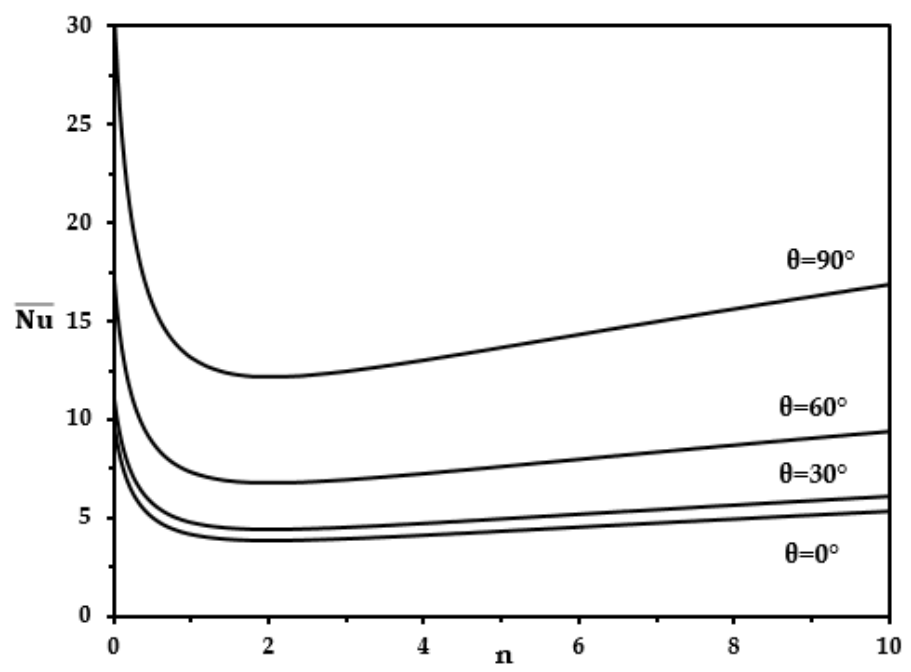

Figure 5:-Variation of the average Nusselt number versus $n$ for various values for $\theta$ with $K^{*}=0.1(R=1)$

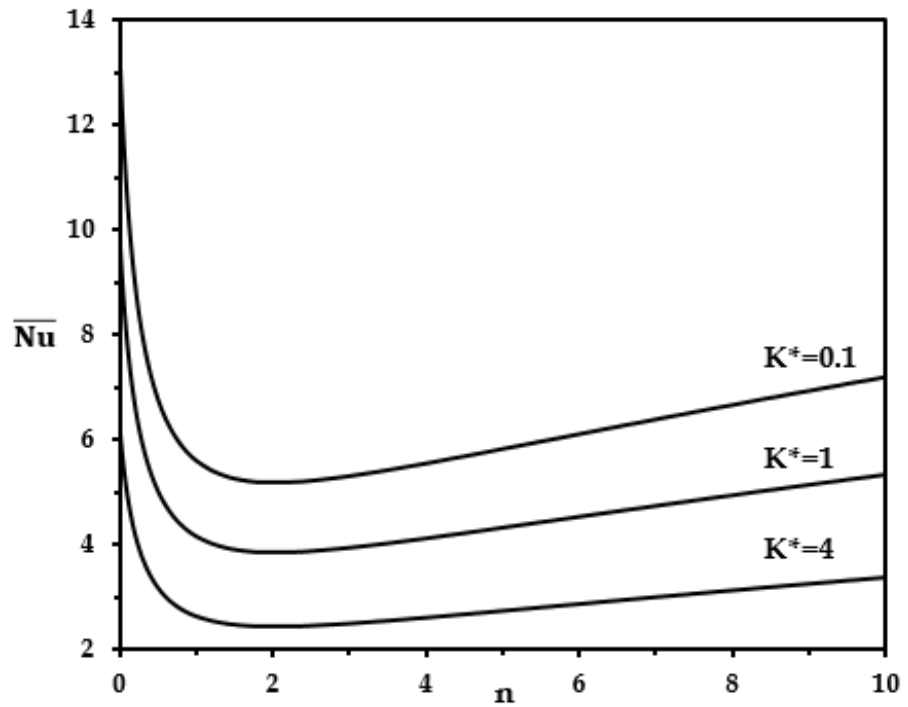

Figure 6:-Variation of the average Nusselt number versus $n$ for various values for $K^{*}$ with $\theta=45^{\circ} \quad(R=1)$

\section{Conclusion:-}

Natural convection in anisotropic porous medium bordering a vertical plate at $4^{\circ} \mathrm{C}$ has been studied. The wallambient temperature difference varies as a power-law variation with $\mathrm{x}$. The major conclusions that emerge are:

1. The anisotropy parameters act both the flow and the heat transfer, a maximum (minimum) convective heat transfer is reached when the orientation of the principal axis with higher permeability of the principal axis with higher permeability of the anisotropic porous medium is parallel (perpendicular) to the gravity;

2. The convective transfer is at its maximum with isothermal temperature in the porous medium $(n=0)$, when the porous medium is not thermally stratified.

3. The convective flow is directed downwards, from the upper end of the vertical plate to the lower end in the thermal boundary layer. The hottest places are the deepest ones;

4. The convective transfer in the case when the vertical plate is at $3.98^{\circ} \mathrm{C}$, depends on $\mathrm{n}$ and reaches its minimum value for $n=0.2$. The relative thickness of the boundary layer is strictly decreasing as $n$ increases.

\section{Nomenclature}

a,b,c Constants in equations (10,11 and 12)

$\mathrm{Ra} \quad$ Rayleigh number

$\Delta \mathrm{T}^{\prime} \quad$ Characteristic temperature difference, $T_{W}^{\prime}-T_{\infty}^{\prime}\left({ }^{\circ} K\right)$

$x^{\prime}, y^{\prime} \quad$ Cartesian coordinate system 


\begin{tabular}{|c|c|}
\hline$x, y$ & Dimensionless coordinate system \\
\hline $\mathrm{V}^{\prime}$ & Velocity of the water film in the porous medium \\
\hline$u^{\prime}, v^{\prime}$ & Darcy velocity components in $x^{\prime}$ and $y^{\prime}$ \\
\hline$u, v$ & Darcy velocity components in $x$ and $y$ \\
\hline $\mathrm{H}^{\prime}$ & Height of the vertical plate \\
\hline$N u_{x \prime}$ & Local Nusselt number \\
\hline $\mathrm{R}$ & Inversion Parameter equation(48) \\
\hline $\mathrm{N}$ & Constant in $\Delta \mathrm{T}^{\prime}=\mathrm{Nx}{ }^{{ }^{\prime}}$ \\
\hline $\mathrm{n}$ & Constant in $\Delta T^{\prime}=\mathrm{Nx}{ }^{\mathrm{n}}$ \\
\hline g & Gravitational acceleration $\left(\mathrm{m} \cdot \mathrm{s}^{-2}\right)$ \\
\hline $\mathrm{h}$ & Convective heat transfer coefficient $\left(\mathrm{W} \cdot \mathrm{m}^{-2} \mathrm{~K}^{-1}\right)$ \\
\hline $\mathrm{T}^{\prime}$ & Temperature $\left({ }^{\circ} \mathrm{K}\right)$ \\
\hline $\mathrm{k}$ & Saturated porous medium thermal conductivity $\left(\mathrm{W} \cdot \mathrm{m}^{-1} \mathrm{~K}^{-1}\right)$ \\
\hline $\mathrm{K}_{1}, \mathrm{~K}_{2}$ & Flow permeability along the principal axes $\left(\mathrm{m}^{2}\right)$ \\
\hline$\overline{\bar{K}}$ & Flow permeability tensor, equation (5) \\
\hline $\mathrm{K}^{*}$ & Anisotropic permeability ratio, equation (13) \\
\hline $\mathrm{P}$ & Pressure $(\mathrm{Pa})$ \\
\hline q & Exponent in the density equation (1) \\
\hline \multirow[t]{2}{*}{$f$} & Similarity stream function variable \\
\hline & Greek symbols \\
\hline$\alpha$ & Thermal diffusivity $\left(\mathrm{m}^{2} . \mathrm{s}^{-1}\right)$ \\
\hline$\beta$ & Thermal expansion coefficient $\left({ }^{\circ} \mathrm{C}^{-2}\right)$ \\
\hline$\delta$ & Boundary-layer thickness (m) \\
\hline$\mu$ & Dynamic viscosity $\left(\mathrm{kg} \cdot \mathrm{m}^{-1} \cdot \mathrm{s}^{-1}\right)$ \\
\hline$\psi$ & Stream function $\left(\mathrm{m}^{2} . \mathrm{s}^{-1}\right)$ \\
\hline$\rho$ & Density of the water $\left(\mathrm{kg} \cdot \mathrm{m}^{-3}\right)$ \\
\hline$v$ & Kinematic viscosity $\left(\mathrm{m}^{2} \cdot \mathrm{s}^{-1}\right)$ \\
\hline$\theta$ & Normalized temperature \\
\hline \multirow[t]{2}{*}{$\eta$} & Independent similarity variable \\
\hline & Subscripts \\
\hline$x^{\prime}$ & Based on $x^{\prime}$ \\
\hline $\max$ & Denotes quantities at maximum \\
\hline$\infty$ & Denotes conditions at infinity \\
\hline \multirow[t]{2}{*}{$\mathrm{w}$} & Refers to the vertical surface \\
\hline & Exponent \\
\hline ، & Variables with dimension \\
\hline
\end{tabular}

\section{References:-}

1. P. Cheng and W. J. Minkowycz, "Free convection about a vertical flat plate embedded in a porous medium with application to heat transfer from a dike," J. Geophys. Res., vol. 82, no. 14, pp. 2040-2044, May 1977.

2. C. H. Johnson and C. Ping, "Possible similarity solutions for free convection boundary layers adjacent to flat plates in porous media,” Int. J. Heat Mass Transf., vol. 21, no. 6, pp. 709-718, Jun. 1978.

3. J. M. Ramilison and B. Gebhart, "Buoyancy induced transport in porous media saturated with pure or saline water at low temperatures," Int. J. Heat Mass Transf., vol. 23, no. 11, pp. 1521-1530, Nov. 1980.

4. V. Kumaran and I. Pop, "Steady free convection boundary layer over a vertical flat plate embedded in a porous medium filled with water at $4^{\circ} \mathrm{C}$," Int. J. Heat Mass Transf., vol. 49, no. 17-18, pp. 3240-3252, Aug. 2006.

5. A. Mahidjiba, L. Robillard, and P. Vasseur, "Onset of convection in a horizontal anisotropic porous layer saturated with water near $4^{\circ}$ c," Int. Commun. Heat Mass Transf., vol. 27, no. 6, pp. 765-774, Aug. 2000.

6. W. Zheng, L. Robillard, and P. Vasseur, "Convection in a square cavity filled with an anisotropic porous medium saturated with water near $4^{\circ}$ C," Int. J. Heat Mass Transf., vol. 44, no. 18, pp. 3463-3470, Sep. 2001.

7. P. Vasseur and G. Degan, "Free convection along a vertical heated plate in a porous medium with anisotropic permeability," Int. J. Numer. Methods Heat Fluid Flow, vol. 8, no. 1, pp. 43-63, Feb. 1998.

8. A. Bejan, Convection Heat Transfer. New York: John Wiley \& Sons, 1984. 